\title{
AVALIAÇÃO DO CUSTO DE IMPLANTAÇÃO DE UM PROGRAMA DE PREVENÇÃO DE MASTITE EM PROPRIEDADES LEITEIRAS NO MUNICÍPIO DE CERRITO - RS
}

\author{
PERES, André Fernandes ${ }^{1}$; \\ PICOLI, Tony ${ }^{2}$; \\ PETER, Cristina Mendes ${ }^{2}$; \\ CZERMAINSKI, Leonardo Arrocho ${ }^{3}$; \\ ZANI, João Luíz ${ }^{4}$.
}

\footnotetext{
${ }^{1}$ Médico Veterinário residente em Saúde Coletiva - Laboratório de Bacteriologia e Saúde Populacional FVET/UFPEL; ${ }^{2}$ Programa de Pós-Graduação em Veterinária - UFPEL; ${ }^{3}$ Acadêmico de Medicina Veterinária UFPEL; ${ }^{4}$ Professor Adjunto do Departamento de Veterinária Preventiva -FVET/UFPEL.
}

\section{RESUMO}

- ste trabalho teve como objetivo avaliar a viabilidade da implantação de um programa - de prevenção da mastite bovina, demonstrando financeiramente os custos e benefícios desse controle. Foram escolhidas três propriedades leiteiras do município de Cerrito - RS, com um total de 82 vacas em lactação. As práticas de manejo da ordenha, prevenção e controle da mastite foram avaliadas. Para a detecção da mastite subclínica foi realizado o California Mastitis Test. Considerando a avaliação das três propriedades e os resultados dos testes, foram estimadas as perdas econômicas e realizado o levantamento de custos para implantação de um sistema de prevenção de mastite nesses estabelecimentos. Foram mensurados os custos com o tratamento da mastite clínica, descarte de vacas por mastite e reparos na máquina de ordenha. Também se estimou as perdas na produção de leite por mastite subclínica. Os resultados mostraram que a implantação do programa permitiria um ganho de $24,8 \%$ sobre a receita mensal média das propriedades, com uma relação custo/benefício favorável, na ordem de 4,37.

Palavras-chave: Prevenção de mastite. Mastite subclínica. Perdas com mastite. 


\section{INTRODUÇÃO}

A mastite é uma reação inflamatória da glândula mamária às agressões bacterianas, químicas, térmicas ou mecânicas e caracteriza-se por alterações físico-químicas, celulares e bacteriológicas do leite, além de modificações patológicas do tecido glandular, sendo a doença infecciosa mais comum do gado leiteiro e que mais causa prejuízos, incluindo a redução da produção e da qualidade do leite, o aumento dos custos com tratamentos e até mesmo o descarte precoce das vacas com mastite crônica. Quando na forma clínica, a doença é de fácil diagnóstico e apresenta sinais como formação de edema no úbere, endurecimento das glândulas afetadas, aumento de temperatura do quarto mamário infectado, reação ao toque em razão da dor, presença de grumos, filamentos, pus e sangue no leite que se torna mais aquoso e sofre descoloração. Porém, o tipo de mastite que mais preocupa é a subclínica, pois é mais difícil de ser identificada por não apresentar sinais clínicos visíveis, tornando-se responsável por aproximadamente 70\% das perdas econômicas decorrentes dessa enfermidade (MAGALHÃES et al., 2006).

Para identificação da mastite subclínica, é realizado o California Mastitis Test (CMT), que é um teste usado mundialmente para este fim, tendo a vantagem de poder ser empregado no momento em que os animais são ordenhados, sendo um indicador indireto da contagem de células somáticas no leite (BRITO et al., 1997). O teste consiste na coleta de leite dos quartos mamários, individualmente, em uma bandeja apropriada, adicionando-se um detergente aniônico neutro, que atua rompendo a membrana das células e liberando o material nucleico (DNA), que apresenta alta viscosidade. De acordo com Ribeiro et al. (2003), a intensidade da reação classifica-se em: negativa (0), reação leve (+), moderada (++) e intensa $(+++)$.

Os programas de controle se baseiam na redução da contaminação bacteriana dos tetos e seu orifício perante limpeza e secagem dos mesmos, antes e depois da ordenha, prevenção de danos físicos causados a estes, tratamento de vacas secas, higiene das mãos do ordenhador, regulagem adequada do vácuo nas ordenhadeiras, higiene e manutenção correta da mesma (HILLERTON, 1996).

Holanda Junior et al. (2005) encontraram uma prevalência de mastite clínica de 4,89\% dos quartos e de subclínica de 43,08\%, em seis rebanhos leiteiros em Araxá - MG. Estimaram que 
as perdas por mastite foram de US\$ 126 por vaca em lactação por ano, sendo que $60 \%$ dessa perda deva-se a redução da produção por mastite subclínica, 15\% por mastite clínica, 12\% por perdas por quartos afuncionais, 5\% por mão de obra extra, 2\% por reposição de animais, $2 \%$ por gasto com medicamentos, $2 \%$ por descarte de leite devido ao tratamento e $2 \%$ por serviços veterinários.

O objetivo deste trabalho foi avaliar a viabilidade de implantar um programa de prevenção de mastite, demonstrando financeiramente os custos e benefícios deste controle.

\section{MATERIAL E MÉTODOS}

Foram avaliadas três propriedades do município de Cerrito - RS. As propriedades A, B e C apresentavam em lactação 22 animais da raça Holandesa, 43 animais da raça Jersey e 17 animais também da raça Jersey, respectivamente. As três propriedades utilizavam ordenha mecânica com balde ao pé sendo avaliadas as práticas de manejo da ordenha, prevenção e controle de mastite.

Para a detecção de mastite subclínica foi realizado o California Mastitis Test (CMT) antes da ordenha. Com base na avaliação das três propriedades e nos resultados dos testes, foram estimadas as perdas econômicas e realizado o levantamento de custos para implantação de um sistema de controle de mastite nesses estabelecimentos, levando em consideração o tratamento de mastite clínica, descarte de vacas por mastite, reparos na máquina de ordenha e as perdas na produção de leite por mastite subclínica. Foram pesquisados valores de produtos e serviços para um programa de controle de mastite, demonstrando o custo para o produtor.

Os cálculos foram realizados considerando trabalhos realizados por Philpot (1967), Foster et al. (1967) e Domingues (1993). Os valores monetários utilizados para os cálculos foram referentes à época da realização do trabalho (abril/2013), sendo que o valor médio pago aos produtores da região era de $R \$ 0,87$ o litro de leite (CEPEA, 2013) e era de $R \$ 2,00$ a cotação do Dólar (BCB, 2013). A estimativa da perda de produção de leite seguiu a orientação de Foster et al. (1967), segundo a qual tetos classificados como reação leve (+) no CMT produzem $19,5 \%$ menos leite do que tetos classificados como negativos (0); tetos 
classificados como reação moderada (++) produzem 31,8\% menos e tetos classificados como reação intensa (+++) produzem $43,4 \%$ menos. Os custos e as receitas foram estimados utilizando-se a média de animais das três propriedades.

\section{RESULTADOS E DISCUSSÃO}

A realização do CMT na totalidade dos animais em lactação das três propriedades revelou que $43,52 \%$ dos tetos avaliados apresentaram resultado negativo, 30,55\% apresentaram uma cruz (+), 13,89\% duas cruzes (++) e 12,04\% três cruzes (+++), conforme está demonstrado na Figura 1.

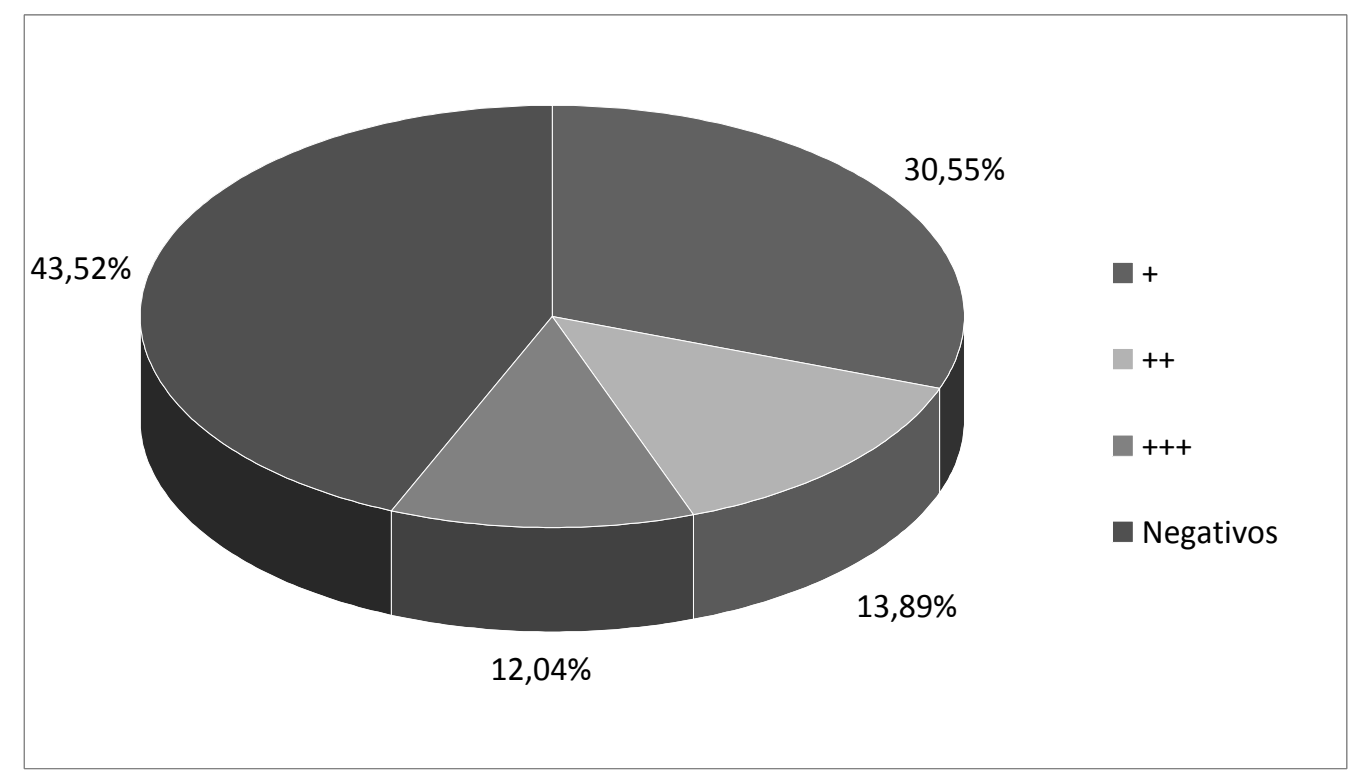

Figura 1. Percentual de tetos classificados através do California Mastitis Test conforme o grau de mastite subclínica em três propriedades leiteiras no município de Cerrito - RS.

Os cálculos dos custos e perdas de cada propriedade foram estimados tomando por base a média das propriedades avaliadas: 27 vacas em lactação com 108 tetos (quartos mamários) ativos. Em média, por propriedade, 47 tetos apresentaram resultado negativo no CMT, 33 tetos apresentaram uma cruz $(+), 15$ tetos duas cruzes $(++)$, e 13 tetos três cruzes $(+++)$.

A produção média diária das três propriedades foi de 14,04 litros/vaca, ou seja, cada teto produzia 3,51 litros/dia. Esses valores serviram de base para estimar a perda de produção leiteira conforme os graus de mastite subclínica encontrados. Em média cada propriedade 
possuía 108 tetos produzindo leite, dos quais 43,52\% (47 tetos) estavam sadios e com plena capacidade produtiva; 30,55\% (33 tetos) apresentaram uma cruz no CMT (+) e sua produção estava reduzida em 19,5\%; 13,89\% (15 tetos) apresentaram duas cruzes (++) e sua produção estava reduzida em 31,8\%; 12,04\% (13 tetos) apresentaram três cruzes (+++) e sua produção estava reduzida em 43,4\%, conforme estimativa proposta por Foster et al. (1967). Partindo dessa lógica podemos estimar a perda de produção diária e mensurar a perda diária e mensal em valores monetários (Tabela 1).

Tabela 1. Estimativa da perda de produção com base no California Mastitis Test teste utilizando a média de três propriedades leiteiras no município de Cerrito - RS em abril de 2013.

\begin{tabular}{ccccccc}
\hline $\begin{array}{c}\text { Reação ao } \\
\text { CMT }\end{array}$ & No de tetos / (\%) & $\begin{array}{c}\text { Produção de leite } \\
\text { litros/dia }\end{array}$ & \multicolumn{2}{c}{ Perda estimada } & $\begin{array}{c}\text { Perda/dia } \\
\text { (R\$) }\end{array}$ & $\begin{array}{c}\text { Perda mensal } \\
\text { estimada (R\$) }\end{array}$ \\
\hline Negativos & $47 /(43,52)$ & 164,97 & --- & --- & --- & -- \\
+ & $33 /(30,55)$ & 115,83 & 19,5 & 28,06 & 24,41 & 732,30 \\
++ & $15 /(13,89)$ & 52,65 & 31,8 & 24,55 & 21,36 & 640,80 \\
++++ & $13 /(12,04)$ & 45,63 & 43,4 & 34.99 & 30,44 & 913,20 \\
\hline Total & $108 /(100)$ & 379,08 & 18,8 & 87,60 & 76,21 & $2.286,30$ \\
\hline
\end{tabular}

* Valor do leite pago ao produtor $\mathrm{R} \$ 0,87 /$ litro.

** Média de 14,04 L/vaca/dia.

A produção média mensal das propriedades avaliadas foi de $11.372,40$ litros de leite, com uma receita média mensal de $\mathrm{R} \$ 9.893,99$ (US\$ 4.946,99). O controle da mastite subclínica permitiria aumentar a produção em 2.628 litros/mês, ou seja, um incremento de R\$ $2.286,36$ (US\$ 1.143,18) na receita mensal do leite.

Entre os vários fatores que compõe o custo total da produção leiteira, destaca-se o gasto com vacas que serão adquiridas para repor ventres que são descartados por mastite. Segundo Holanda Junior et al. (2005), o descarte anual de vacas por mastite é de 13\%, em um rebanho de 27 vacas serão descartadas quatro vacas por ano. Considerando que o preço de mercado para reposição de uma vaca leiteira com produção média de 20 L/dia, na região, em abril/2013, foi de $\mathrm{R} \$ 4.000,00$ (US\$2.000,00), e que o valor pago por uma vaca leiteira de descarte com média de $500 \mathrm{~kg} / \mathrm{PV}$ foi de $\mathrm{R} \$ 3,00 / \mathrm{kg} / \mathrm{PV}(\mathrm{R} \$ 1.500,00$ ou US\$750,00), temos 
um custo de $\mathrm{R} \$ 2.500,00$ (US\$1.250,00) por vaca de reposição. Por ano, haverá um dispêndio de $R \$ 10.000,00$ (US\$ 5.000,00), ou R\$ 833,33 (US\$ 416,66) ao mês.

O mesmo parâmetro utilizado para estimar a taxa de descarte de vacas por mastite (13\%) foi escolhido para mensurar o gasto com tratamento de mastite clínica. Com isso temos que quatro vacas serão tratadas uma vez ao ano, por três dias consecutivos, totalizando 12 bisnagas por vaca/ano. O gasto estimado com esse tratamento foi de $\mathrm{R} \$ 336,00 /$ ano ou $\mathrm{R} \$$ 28,00 ao mês. Ao mesmo tempo devemos considerar a perda de receita referente ao descarte do leite durante o tratamento e período de carência dos produtos utilizados. Para esse cálculo foi considerada a perda de receita do leite de quatro vacas durante 8 dias ( 3 dias de tratamento e 5 dias de carência), ou seja, 449,28 L/ano que representam $R \$$ 390,87/ano ou $\mathrm{R} \$ 32,57$ ao mês.

Tomando como base o incremento na receita de $\mathrm{R} \$ 2.286,36$, resultante do controle da

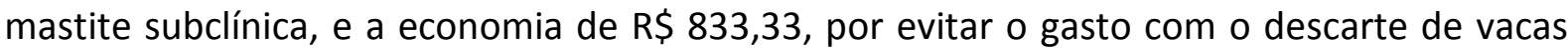
com mastite clínica, mais a economia de $\mathrm{R} \$ 60,57$, referentes ao tratamento e descarte do leite de vacas com mastite clínica, temos uma receita a maior de $\mathrm{R} \$ 3.180,26$ (US\$ 1.590,13) por mês.

O custo mensal para a implantação de um programa de prevenção da mastite está demonstrado na Tabela 2. 
Tabela 2. Custo estimado para implantação de um programa de prevenção de mastite para propriedades com 27 vacas em lactação.

\begin{tabular}{|c|c|c|c|c|}
\hline Produto/Serviço & Unidades/ano & Valor $\mathbf{R} \$^{*}$ & Custo/Mês R\$ & Custo/Ano R\$ \\
\hline Solução de lodo pronta para pré-ordenha' & 388,8 L/ano & $9,00 / L$ & 291,60 & $3.499,20$ \\
\hline Solução de lodo pronta para pós-ordenha' & 388,8 L/ano & 9,00/L & 291,60 & $3.499,20$ \\
\hline Papel - toalha² & 77.760 fol./ano & 0,01/folha & 64,80 & 777,60 \\
\hline Caneca Telada ${ }^{3}$ & 1 un./ano & 15,00 & 1,25 & 15,00 \\
\hline Copo Dipping ${ }^{3}$ & 1 un./ano & 25,00 & 2,08 & 25,00 \\
\hline Avaliação da ordenhadeira ${ }^{4}$ & $1 \mathrm{vez} / \mathrm{ano}$ & 35,00 & 2,92 & 35,00 \\
\hline Troca do conjunto de borrachas das teteiras ${ }^{4}$ & $1 \mathrm{vez} / \mathrm{ano}$ & 120,00 & 10,00 & 120,00 \\
\hline Bisnaga para tratamento de vacas secas ${ }^{5}$ & 108 bis./ano & $7,00 /$ un. & 63,00 & 756,00 \\
\hline TOTAL & & & 727,25 & $8.727,00$ \\
\hline
\end{tabular}

* Valores comerciais em Pelotas - RS, em abril de 2013.

1. O volume médio de solução de lodo pré e pós-ordenha é de $540 \mathrm{ml}$ para cada 27 vacas/ordenha.

2. São utilizadas quatro folhas de papel-toalha por vaca, ou seja, uma folha para cada teto por ordenha.

${ }^{3}$. As canecas de pré e pós-dipping, assim como a caneca telada de fundo preto, recomenda-se trocar uma vez ao ano.

4. É recomendada, no mínimo, uma visita anual para avaliação do equipamento de ordenha, sendo que o conjunto de teteiras suporta aproximadamente 2.500 ordenhas.

5. Foram selecionadas quatro formulações comerciais para o tratamento preventivo de vacas secas contra a mastite: Cloxacilina benzatina, Ampicilina sódica, Cloxacilina sódica e Espiramicina /Neomicina.

O custo de implantação do programa de prevenção da mastite foi estimado em $\mathrm{R} \$ 727,25$ ao mês, que subtraído do incremento na receita mensal, que foi da ordem de $\mathrm{R} \$ 3.180,26$, resulta num saldo de $\mathrm{R} \$ 2.453,01$ (US\$ 1.226,50) ao mês.

\section{CONCLUSÕES}

A implantação de um programa de prevenção de mastite, ao custo de $\mathrm{R} \$ 727,25$ (US\$ 363,62) mensais, permitiria aumentar a produção em 2.628 litros/mês, ou seja, um incremento de $\mathrm{R} \$ 2.286,36$ (US\$ 1.143,18). Ao mesmo tempo haveria uma economia de $\mathrm{R} \$$ 893,90 , referentes aos gastos com reposição de vacas, tratamento de mastite e descarte de leite. O saldo final seria de $R \$ 2.453,01$ (US\$ 1.226,50), ou seja, um ganho de $24,8 \%$ sobre a receita mensal, considerando a média das três propriedades avaliadas do município de 
Cerrito - RS. A relação custo/benefício da implantação do programa foi favorável, na ordem de 4,37 .

\section{ESTIMATED COST FOR THE IMPLEMENTATION OF A PROGRAM OF MASTITIS PREVENTION IN DAIRY FARMS IN THE CITY OF CERRITO-RS, BRAZIL}

\section{ABSTRACT}

$\mathrm{T}$

his paper aimed to evaluate the viability of implementing a program for the prevention of bovine mastitis, demonstrating financially the costs and benefits of this control. Three dairy farms were chosen from the municipality of Cerrito - RS, with a total of 82 lactating cows. The practices of the milking management, prevention and control of mastitis were evaluated. For the detection of subclinical mastitis the California Mastitis Test was held. Considering the assessment of the three farms and the test results, the economic losses were estimated and a survey of costs was conducted for implementing a system for the prevention of mastitis in these establishments. The production losses with the treatment of clinical mastitis, disposal of cows due to mastitis and repairs in the milking machine were estimated. The losses in milk production due to subclinical mastitis were also estimated. The results showed that the implementation of the program allowed a gain of $24.8 \%$ on the average monthly income of the farms, with a favorable cost / benefit ratio of 4.37 .

Keywords: Prevention of mastitis. Subclinical mastitis. Mastitis control.

\section{EVALUACIÓN DEL COSTO DE IMPLEMENTACIÓN DE UN PROGRAMA DE PREVENCIÓN DE MASTITIS EN PROPIEDADES LECHERAS EN EL MUNICIPIO DE CERRITO - RS, BRAZIL}

\section{RESUMEN}

E ste trabajo tuvo como objetivo evaluar la viabilidad de implementar un programa de prevención de mastitis bovina, demostrando financieramente los costos y beneficios de este control. Tres propiedades fueron visitadas en el municipio de Cerrito - RS, con un total de 82 vacas en lactación, donde fueron evaluadas las prácticas de manejo del ordeñe, de prevención y control de mastitis. Para la detección de mastitis subclínica fue realizado el California Mastitis Test. Considerando la evaluación de las tres propiedades y los resultados de las pruebas, fueron estimadas las pérdidas económicas y se realizó el levantamiento de costos para la implementación de un sistema de prevención de mastitis en esos establecimientos. Fueron estimados los costos del tratamiento de la mastitis clínica, 
descarte da las vacas por mastitis y reparación da la máquina de ordeñe. También se estimaron las pérdidas en la producción de leche por mastitis subclínica. Los resultados mostraron que la implementación del programa permitió una ganancia de $24,8 \%$ en el ingreso promedio mensual de las propiedades, con una relación de costo/beneficio favorable en el orden de 4,37.

Palabras clave: Prevención de mastitis. Mastitis subclínica. Pérdidas con mastitis.

\section{REFERÊNCIAS}

BCB - BANCO CENTRAL DO BRASIL. Câmbio: mais moedas, taxas de câmbio. Brasília, 2013. Disponível em: http://www4.bcb.gov.br/pec/taxas/port/ptaxnpesq.asp?id=txcotacao Acesso em out. 2013.

BRITO, J. R. F.; CALDEIRA, G. A. V.; VERNEQUE, R. S.; BRITO, M. A. V. P. Sensibilidade e especificidade do "California Mastitis Test" como recurso diagnóstico da mastite subclínica em relação à contagem de células somáticas. Pesquisa Veterinária Brasileira, v. 17, n. 2, p. 49-53, 1997.

CEPEA - CENTRO DE ESTUDOS AVANÇADOS EM ECONOMIA APLICADA. Leite: preços ao produtor, valores nominais do leite: $\mathbf{R} \$$ /Litro. São Paulo, 2013. Disponível em: http://cepea.esalq.usp.br/leite/?page=155 Acesso em out. 2013.

DOMINGUES, P. F. Produção de leite e mastite bovina subclínica por Staphylococcus aureus, Staphylococcus epidermidis, Streptococcus agalactae, e Corynebacterium bovis. Botucatu: UNESP, 1993. 38p. Dissertação. (Mestrado em Zootecnia) - Universidade Estadual Paulista "Júlio de Mesquita Filho", 1993.

FORSTER, T. L., ASHWORTH, V. S., LUEDCKE, L. O. Relations ship between California Mastitis Test reaction and production and composition of milk from opposite quarters. Journal of Dairy Science, v. 50, n. 05, p. 675-682, 1967.

HILLERTON, J. E. Controle da mastite bovina. In: WORKSHOP SOBRE PROGRAMA DE CONTROLE INTEGRADO DA MASTITE BOVINA, 1996, Juiz de Fora. Anais. Juiz de Fora: Embrapa, 1996, p. 6-21.

HOLANDA JUNIOR, E. V.; MADALENA, F. E.; HOLANDA, E. D.; MIRANDA, W. M.; SOUZA, M. R. Impacto econômico da mastite em seis fazendas de Araxá - Minas Gerais, Brasil. Archivos Latinoamericanos de Produción Animal, v. 13, n. 02, p. 63-69, 2005.

MAGALHÃES, H. R.; EL FARO, L.; CARDOSO, V. L.; PAZ, C. C. P.; CASSOLI, L. D.; MACHADO, P. F. Influência de fatores de ambiente sobre a contagem de células somáticas e sua relação com perdas na produção de leite de vacas da raça Holandesa. Revista Brasileira de Zootecnia, v. 35, n. 05, p. 415-421, 2006. 
PHILPOT, W. N. Influence of subclinical mastitis on milk production and milk composition. Journal of Dairy Science, v. 50, n. 15, p. 978, 1967.

RIBEIRO, M. E. R.; PETRINI, L. A.; AITA, M. F.; BALBINOTTI, M.; STUMPF JR, W.; GOMES, J. F.; SCHRAMM, R. C.; MARTINS, P. R.; BARBOSA, R. S. Relação entre mastite clínica, subclínica infecciosa e não infecciosa em unidades de produção leiteira na região sul do Rio Grande do Sul. Revista Brasileira de Agrociência, v. 09, n. 03, p. 287-290, 2003.

VIANA, J. G. A.; ZEN, B.; KARLEC, F.; SOUZA, R. S. Comportamento dos preços históricos do leite no Rio Grande do sul, Brasil. Ciência e Agrotecnologia, v. 34, n. 02, p. 451-460, 2010.

Autor para correspondência: André Fernandes Peres. Médico Veterinário residente em Saúde Coletiva - Laboratório de Bacteriologia e Saúde Populacional - 